\title{
Bank Voles in Southern Eurasia: Vicariance and Adaptation
}

\section{Ronan Ledevin, Pascale Chevret, Zeycan Helvaci, Johan R. Michaux \& Sabrina Renaud}

\section{Journal of Mammalian Evolution}

ISSN 1064-7554

Volume 25

Number 1

J Mammal Evol (2018) 25:119-129

DOI 10.1007/s10914-016-9368-3
JOURNAL OF MAMMALIAN EVOLUTION

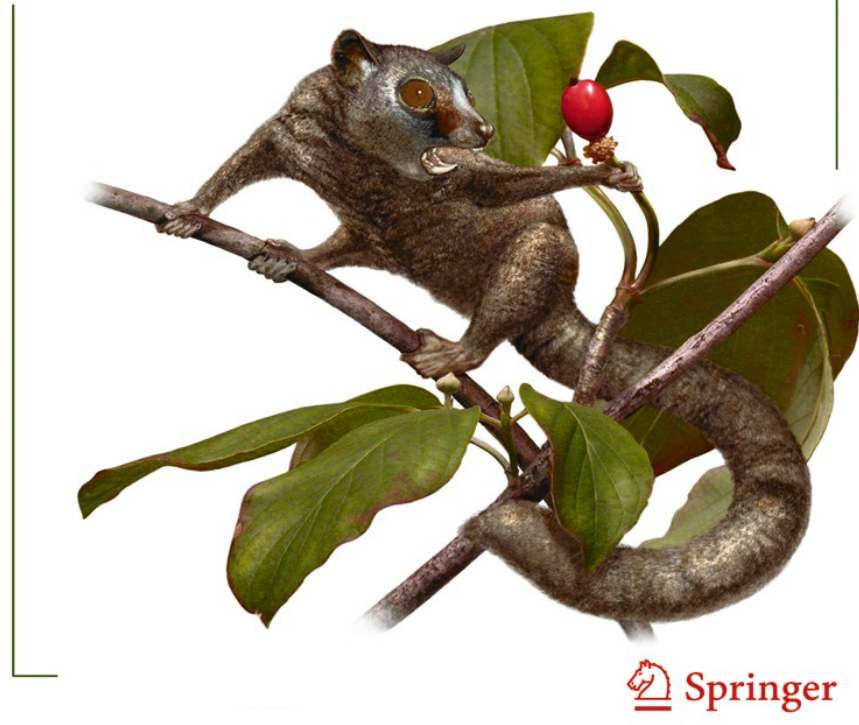


Your article is protected by copyright and all rights are held exclusively by Springer Science +Business Media New York. This e-offprint is for personal use only and shall not be selfarchived in electronic repositories. If you wish to self-archive your article, please use the accepted manuscript version for posting on your own website. You may further deposit the accepted manuscript version in any repository, provided it is only made publicly available 12 months after official publication or later and provided acknowledgement is given to the original source of publication and a link is inserted to the published article on Springer's website. The link must be accompanied by the following text: "The final publication is available at link.springer.com". 


\title{
Bank Voles in Southern Eurasia: Vicariance and Adaptation
}

\author{
Ronan Ledevin $^{1,2}$ • Pascale Chevret ${ }^{1} \cdot$ Zeycan Helvaci $^{3,4} \cdot$ Johan R. Michaux $^{3}$. \\ Sabrina Renaud ${ }^{1}$ (i)
}

Published online: 10 December 2016

(C) Springer Science+Business Media New York 2016

\begin{abstract}
Phylogeographic lineages are interpreted as the product of repeated isolation in glacial refugia, leading to vicariant differentiation. Being restricted to a given geographic area could also promote adaptive divergence in response to local conditions. The role of phylogeny and climate in the evolution of the bank vole (Myodes glareolus) was investigated here, focusing on molar tooth shape, a morphological feature related to the exploitation of food resources. A balanced role of phylogeny and climate was demonstrated. Response to environmental factors led to morphological convergence of bank voles from different lineages living in similar environments, and to within-lineage divergence in extreme environments. An important interaction of climate and phylogeny was found, suggesting that each lineage is living in a particular environment. This lineage-specific adaptation to a range of environmental conditions may have conditioned the potential of post-glacial recolonization of each lineage. Morphological covariation with environmental conditions further highlights the potential of adaptation of this species.
\end{abstract}

Electronic supplementary material The online version of this article (doi:10.1007/s10914-016-9368-3) contains supplementary material, which is available to authorized users.

Sabrina Renaud

sabrina.renaud@univ-lyon1.fr

1 Laboratoire de Biométrie et Biologie Evolutive, UMR5558, Université Claude Bernard Lyon 1, CNRS, 69100 Villeurbanne, France

2 Present address: UMR5199 PACEA, Université de Bordeaux, 33615 Pessac, France

3 Laboratoire de génétique de la conservation, Université de Liège, Institut de Botanique (Bat. 22), 4000 Liège, Belgium

4 Aksaray Üniversitesi Fen Edebiyat Fakültesi, 68100 Merkez/ Aksaray, Turkey
Keywords Myodes glareolus · Geometric morphometrics · Morphological convergence $\cdot$ Tooth shape $\cdot$ Third lower molar - Arvicoline rodent

\section{Introduction}

The response to environmental variation can involve adaptation, but also shifts in the geographic distribution, avoiding need for adaptation by tracking favorable environmental conditions (Eronen and Rook 2004). Phylogeographic studies have shown that many species indeed responded to glacialinterglacial fluctuations through changes in their distribution area, temperate species finding refugia in regions of lower latitudes. The repeated phases of isolation led to the divergence of phylogeographic lineages (Taberlet et al. 1998; Hewitt 1999). Random effects related to isolation in vicariance may be sufficient to drive such a differentiation. Accordingly, the role of geographic barriers in shaping current phylogeographic lineages has been highlighted (Michaux et al. 2003). The role of adaptation in the refugial environments, and/or during recolonizations, cannot be ignored, although it is still difficult to show at the genomic level (Filipi et al. 2015). During invasions, evidence of adaptation can however be traced even on extremely short time scales (White et al. 2013). The respective role of phylogeny and related neutral divergence, and adaptation in shaping divergence is therefore debated (Travisano et al. 1995; Keller and Taylor 2008; Ledevin et al. 2016). Considering phenotypic characters, more directly under selection due to their evident interface with the environment, may be a valuable alternative to investigate how phylogeny and environment may concur to the current geographic structure of species.

The bank vole Myodes (formerly known as Clethrionomys) glareolus is a Eurasian forest-dwelling rodent. To the south of 
its distribution, it occurs in Mediterranean peninsulas and the southern coast of the Black Sea (Fig. 1). Having acted as glacial refugia, these southern areas nowadays host several lineages, providing the opportunity to investigate possible convergence in similar Mediterranean environments. The third upper molar (UM3) was the morphological feature of interest. Being part of the molar row, it is involved in food processing. As such, it has the potential to trace adaptation to food resources, themselves dependent on environmental conditions (Piras et al. 2009). Teeth are also good taxonomic markers in arvicoline rodents (Tesakov 1996) and could also trace non-adaptive phylogenetic divergence. The shape of the tooth was quantified using geometric morphometrics. The phylogenetic relationships between localities studied with morphometrics were assessed based on published cytochrome $b$ (cyt $b$ ) gene sequences. The environment at each place of morphometric sampling was described by a range of bioclimatic variables. The three datasets were compared using linear models and coinertia analyses in order to determine how shape related to the two potential drivers of differentiation, phylogeny and environment.

\section{Material}

\section{Morphometric Sampling}

Morphometric analyses were performed on 166 bank vole specimens from 20 Eurasian localities (Table 1, Fig. 1). Our sampling encompassed various locations at the southern border of the bank vole distribution (Fig. 1): the Iberian and Italian peninsulas, including the Gargano promontory (Italy) where a separate lineage has been recently described (Colangelo et al. 2012); and the Turkish border of the Marmara Sea. All these locations correspond to Mediterranean climates. Localities exposed to oceanic, alpine, and continental climates were further considered as comparison.

The specimens were attributed to the phylogeographic lineage documented at the same place. The specimens from the Basque locality of Lantabat, for which no genetic information was available, were affiliated with the same genetic data as the neighboring Armandarits locality, $5 \mathrm{~km}$ away. Note that the formerly described Basque lineage (Deffontaine et al. 2009) has been shown to be invalid (Filipi et al. 2015), being based on the occurrence of pseudogenes. All Basque specimens were therefore attributed to the Mediterranean lineage, as other French and Spanish specimens.

All individuals were considered as adults and sub-adults based on the criterion that the third upper molars were fully erupted (occurring at weaning). As no sexual dimorphism has been documented for tooth morphology in bank voles (Ledevin et al. 2010a), males and females were pooled in all subsequent analyses.

Specimens are stored at the Laboratoire de Biométrie et Biologie Evolutive, Lyon University, France, the Institut de Botanique, Liège University, Belgium, the Centre de Biologie et Gestion des Populations, Baillarguet, France and the Laboratory for Systematic of Vertebrate Animals, Ankara University, Turkey (Table 1).

\section{Genetic Sampling}

Cytochrome $b$ DNA sequences of $M$. glareolus were retrieved from Genbank and put into two datasets. (1) A general dataset with all cyt $b$ of $M$. glareolus available in Genbank was used to clarify the relationships of the different lineages of the bank vole in the Mediterranean area. (2) A smaller dataset was designed to include only sequences matching the morphometric sampling (Fig. 1), the goal being to have a genetic/ morphometric match per geographic area (each locality and surrounding area when available) (Table 1).
Fig. 1 Map of the populations included in the genetic and morphometric analyses. Colors indicate the phylogenetic lineages, according to previous studies (Deffontaine et al. 2005; Wójcik et al. 2010; Colangelo et al. 2012). The grey shading indicates the distribution area of the bank vole [after (Amori et al. 2008)]

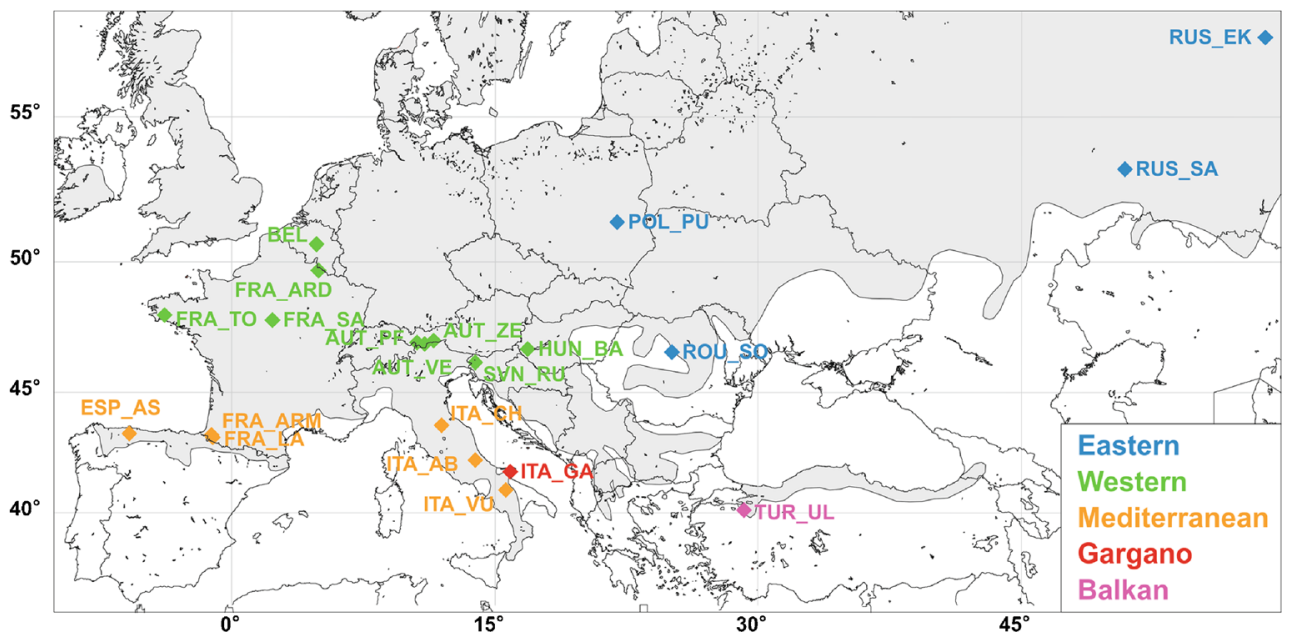


Table 1 Localities of the bank voles considered in the morphometric analysis, with their abbreviated code, country, latitude and longitude; number of third upper molars measured (Nmorpho); corresponding localities considered in the phylogenetic analysis with their accession numbers

\begin{tabular}{|c|c|c|c|c|c|c|c|c|}
\hline Code & Morphological locality & Country & Latitude & Longitude & Storage & $\mathrm{N}_{\text {morpho }}$ & Genetic locality & Accessions \\
\hline AUT_PF & Pfunds & Austria & 46.98 & 10.54 & IBL & 4 & Pfunds & EU483557, EU483558, HQ288331 \\
\hline AUT_VE & Ventetal & Austria & 46.92 & 10.99 & IBL & 3 & Ventetal & EU483559 \\
\hline AUT_ZE & Zemmtal & Austria & 47.05 & 11.49 & IBL & 8 & Ginzling & HQ288328, HQ288329, HQ288330 \\
\hline $\mathrm{BEL}^{*}$ & $\begin{array}{l}\text { Andenne, Colonster, } \\
\text { Dahlem, Liège, } \\
\text { Leernes, Virelles }\end{array}$ & Belgique & 50.30 & 4.86 & IBL & 20 & $\begin{array}{l}\text { Beaumont, Colonster, } \\
\text { Dahlem, Leernes, } \\
\text { Virelles }\end{array}$ & $\begin{array}{l}\text { EU483579, AJ639661 AJ867973, } \\
\text { AJ867965, HQ288332, } \\
\text { HQ288333, HQ288334 }\end{array}$ \\
\hline ESP_AS & Asturias & Spain & 43.36 & -5.85 & IBL & 12 & Asturias & AJ867979 \\
\hline FRA_ARD & Ardennes & France & 49.7 & 4.94 & LBBE & 6 & Ardennes & HQ288373, HQ288374, HQ288375 \\
\hline FRA_ARM & Armendarits (Basque Country) & France & 43.3 & -1.17 & CBGP & 12 & Armendarits & KM892840, KM892841 \\
\hline FRA_LA & Lantabat (Basque Country) & France & 43.3 & -1.12 & CBGP & 7 & Armendarits & KM892840, KM892841 \\
\hline FRA_SA & Saint-Aignan-des-Gués & France & 47.84 & 2.32 & IBL & 10 & Saint-Aignan-des-Gués & $\mathrm{EF} 408072$ \\
\hline FRA_TO & Tourch & France & 48.03 & -3.83 & CBGP & 14 & Tourch & $\begin{array}{l}\text { HQ288393, HQ288394, HQ288395, } \\
\text { HQ288396 }\end{array}$ \\
\hline HUN_BA & Bak (Zala) & Hungary & 46.73 & 16.85 & IBL & 4 & Zala & EU483539, EU483540 \\
\hline ITA_ABVU* & Abbruzo & Italy & 42.24 & 13.89 & LBBE & 2 & Abbruzo & EU483554, EU483555 \\
\hline ITA_ABVU* & Vultures Mountains & Italy & 40.98 & 15.63 & LBBE & 2 & Vultures Mountains & EU483549, EU483550 \\
\hline ITA_CH & Chiusi della Verna (Tuscany) & Italy & 43.7 & 11.94 & LBBE & 6 & Chiusi della Verna & AJ639663, AJ639664 \\
\hline ITA_GA & Gargano & Italy & 41.77 & 15.85 & LBBE & 11 & Gargano, Apulia & $\begin{array}{l}\text { EU483546, EU483547, EU483548, } \\
\text { KM892834 }\end{array}$ \\
\hline POL_PU & Pulawy & Poland & 51.42 & 21.97 & IBL & 8 & Pulawy, Lublin & AJ639669, HQ288405 \\
\hline ROU_SO & Sovata (Targu Mures) & Romania & 46.6 & 25.08 & IBL & 9 & Targu Mures & $\begin{array}{l}\text { AJ867950, AJ867956, AJ867960, } \\
\text { EF408076, EF408077, EF408078 }\end{array}$ \\
\hline RUS_EK & Ekaterinburg (Sverdlosk) & Russia & 57.47 & 59.22 & IBL & 5 & Sverdlosk & $\begin{array}{l}\text { EU232142, EU232153, EU232154, } \\
\text { EU232155, EU035666, EU035667, } \\
\text { EU035689, JF714753, JF714754 }\end{array}$ \\
\hline RUS_SA & Samara & Russia & 53.25 & 50.92 & IBL & 8 & Samara & $\begin{array}{l}\text { AF367080, AF367081, AF367082, } \\
\text { AY062900, AY062901, AY062902, } \\
\text { AY062903, AY062904, AY062905, } \\
\text { AY062906, AY062907 }\end{array}$ \\
\hline SVN_RU & Rut & Slovenia & 46.2 & 13.89 & IBL & 3 & Livek & AJ867953 \\
\hline TUR_UL & Uludag mountains & Turkey & 40.19 & 29.06 & LSVAA & 8 & Bursa, Uludag mountains & KM892817, AJ639697 \\
\hline
\end{tabular}

Localities indicated with an asterisk (*) were pooled because of low sample size. The place of storage of the specimens is also indicated The locality used for the genetic match with the morphometric locality is further indicated, together with accession numbers

$I B L$ Institut de Botanique, Liège University, Belgium, $L B B E$ Laboratoire de Biométrie et Biologie Evolutive, Lyon University, France, $C B G P C$ Centre de Biologie et Gestion des Populations, Baillarguet, France, LSVAA Laboratory for Systematic of Vertebrate Animals, Ankara University, Turkey

\section{Methods}

\section{Network Analysis of the General Dataset}

We collected all cyt $b$ sequences of $M$. glareolus available in Genbank. The sequences were aligned with MUSCLE implemented in Seaview (Gouy et al. 2010). We removed the sequences belonging to the Ural lineage (harbouring rutilus mitochondrial genome) (Deffontaine et al. 2005), known pseudogenes sequences (Filipi et al. 2015), and sequences shorter than $850 \mathrm{bp}$ and/or containing several ambiguous sites. Our final alignment was restricted to a common length of 866 sites (positions with missing data were removed) and comprised 979 sequences.

To visualize the relationship between the different lineages of $M$. glareolus, a haplotype network was inferred for the general dataset using the median-joining algorithm as implemented in PopART (Leigh and Bryant 2015).

\section{Phylogenetic Analyses of the Dataset Matching Morphometric Sampling}

The alignment was checked by eye and trimmed at both ends to remove portions with more than $50 \%$ missing data. As a result, this dataset included 68 sequences with 996 positions common to all sequences.

The phylogenetic tree was reconstructed using maximum likelihood with PhyMl 3.0 (Guindon et al. 2010) under the model selected with jModelTest (Darriba et al. 2012) using the Akaike criterion (AIC) (Akaike 1973) [TIM1 (option $\mathrm{m}=012230)+\mathrm{I}+\mathrm{G}]$. Node robustness was estimated using 1000 bootstrap replicates providing bootstraps percentages (BP).

The cyt $b$ distance matrix based on this tree was analyzed using a Principal Coordinate Analysis (PCOA), providing multivariate axes describing the phylogenetic relationships to be compared with morphometric results. 


\section{Morphometric Analysis}

The two dimensional outline of the occlusal surface of the left UM3 (or the mirror image of the right UM3) was digitized, sampling the coordinates of 64 points at equal curvilinear distance along the outline.

The molars of the arvicoline rodents are composed of successive triangles leading to a very indented outline. The starting point was defined at the minimum of curvature between the first and second anterior labial triangles. The Elliptic Fourier transform is an adequate method to describe such outlines (Navarro et al. 2004). This method is based on the separate Fourier decompositions of the incremental changes of the $x$ - and $y$-coordinates as a function of the cumulative length along the outline (Kuhl and Giardina 1982). Any harmonic corresponds to four coefficients: $A_{n}$ and $B_{n}$ for $x$, and $C_{n}$ and $D_{n}$ for $y$, defining an ellipse in the $x y$-plane. The first harmonic ellipse corresponds to the best-fitting ellipse to the outline and its area was used to standardize the Fourier coefficients for size differences. The major axis of the first harmonic ellipse was chosen as a new $x$-axis to adjust the orientation of the outline. After standardization, the coefficients $A_{1}, B_{1}$ and $C_{1}$ mostly correspond to residuals that should not be included in subsequent statistical analyses (Renaud et al. 1996). The coefficient $D_{1}$ corresponds to the minor axis of the first ellipse and hence, to relevant shape information, namely the general elongation of the object. It was thus included in the analyses (Michaux et al. 2007).

The first ten harmonics provide an adequate description of an arvicoline tooth outline (Navarro et al. 2004; Ledevin et al. 2010a, 2010b). The shape of each UM3 was thus described by 37 variables: nine harmonics (from the second to the tenth) per four coefficients, plus the coefficients $D_{1}$. Visualizations of shape differences among groups were obtained using the inverse Fourier method (Rohlf and Archie 1984).

Fourier analyses and visualizations were performed under $\mathrm{R}$ (R_core_team 2015) using the package Momocs (Bonhomme et al. 2014).

\section{Multivariate Analysis of Shape Differences}

A Canonical Variate Analysis (CVA) including all the specimens was performed on the variance-covariance matrix of the 37 Fourier coefficients in order to determine the patterns of morphological differentiation. CVA aims at separating groups by maximizing the between-group to within-group variance ratio. It appeared adequate here, because within-group variation in the bank vole UM3 was shown to contain variation due to wear (Guérécheau et al. 2010) and to developmental processes independent of the lineages (Ledevin et al. 2010b). The location was chosen as a grouping variable, because it appeared as related to field data and not directly to the phylogeographic lineages.

The differences between localities were tested using a multivariate analysis of variance (MANOVA).
These analyses were performed using the $\mathrm{R}$ packages ade 4 (Dray and Dufour 2007) and Morpho (Schlager 2014).

\section{Relationships of Shape with Phylogeny and Climate}

Phylogeny and climate were considered as potential explanatory variables of morphometric variations. Their effects were investigated using a general linear model. Three sets of shape descriptors (dependent variables) where investigated: the $37 \mathrm{FCs}$; the first principal components of a PCA on the FCs; the first canonical axes of the CVA. Independent variables were the following. Phylogenetic relationships were estimated by the first axes of a Principal Coordinate Analysis (PCOA) performed on the cyt $b$ distance matrix based on the dataset with a genetic/ morphometric match (Table 1; Suppl. Fig. 1). The R 'ape' package (Paradis et al. 2004) was used for the calculation. The climatic regime at each locality was estimated using the 19 climatic data available (http://www.worldclim.org/bioclim) that were extracted from the WorldClim database with a resolution of 2.5 arc-minutes using the 'raster' package (Hijmans and van Etten 2014). A principal component analysis (PCA) on the correlation matrix of the climatic variables was performed to summarize these partly redundant data. The first PCs were retained as explanatory variables in the model.

Finally, to assess the percentage of variance corresponding to between vs. within group variance in the residual shape variation, a between-group PCA (bgPCA) was performed on the residuals of the model based on the set of FCs. The bgPCA was performed with ade4 (Dray and Dufour 2007).

\section{Covariation between the Datasets}

Beyond the percentage of morphological variance explained by phylogeny and climate, the way the morphometric variation is related to these factors may be informative about underlying evolutionary processes. Morphological convergence, for instance, would correspond to a less morphological differentiation between groups than expected based on genetics. Coinertia analyses were used in order to visualize such covariation between the morphometric vs. the genetic, and vs. the climatic datasets [function coinertia in ade4 (Dray and Dufour 2007)]. This approach aims at finding orthogonal vectors (i.e., coinertia axes) maximizing the covariance between two datasets (Dodélec and Chessel 1994; Dray et al. 2003) allowing their projection in a common space.

\section{Data Availability Statement}

Data generated or analyzed during this study are included in this published article as supplementary information file (Suppl. Table 1). 


\section{Results}

\section{Phylogeny}

The phylogenetic network (Fig. 2) supported the phylogeographic lineages formerly described in the literature (Deffontaine et al. 2005; Kotlík et al. 2006; Wójcik et al. 2010; Colangelo et al. 2012). The Balkan lineage, to which belongs the Turkish locality of Uladag Mountains, is well defined. The Gargano lineage (Colangelo et al. 2012) is also well isolated, although its relationship with the other clades is not well resolved. Note that its peculiarity cannot be due to a pseudogene, frequent in this species, because one of the cyt $b$ sequences corresponds to a portion of a complete mitochondrial genome from the very same area (Filipi et al. 2015). Finally, the Mediterranean lineage also appears as well differentiated from the other clades. It tends to differentiate into an Iberian sub-lineage, including specimens from southern France, and an Italian sub-lineage.

\section{Pattern of Molar Shape Differentiation}

Bank voles are well differentiated in molar shape between localities (MANOVA: $P<0.0001$ ). This pattern of divergence can be summarized on the first three axes of a Canonical Variate Analysis (Fig. 3a; CA1 $=17.5 \%, \mathrm{CA} 2=15.5 \%$, $\mathrm{CA} 3=11.8 \%$ ).

The Western lineage displays a central position in the morphospace and most variation among localities, possibly because of its most extensive sampling. The Eastern lineage is differentiated in shape from all other lineages along CA1 and CA2. It is characterized by slender, smoothly undulating molars (Fig. 3b). Localities from the Mediterranean lineage tend to diverge in another direction along CA1, but they are loosely scattered. The northern Italian locality (ITA CH) falls within Western samples. The Spanish Asturias (ESP_AS) diverges from the Italian localities along CA2. The two samples from the Basque Country (FRA_ARM and FRA_LA) are close together in the morphospace, and intermediate between Spanish Asturias and the central Italian sample (ITA_ABVU). The Gargano population (ITA_GA) appears to differ along all first three axes. It is isolated in the morphospace in the same direction as most groups of the Mediterranean lineage and it is particularly close to the central Italian sample (IT_ABVU). Molars of Mediterranean and Gargano bank voles are broad with deeply indented triangles. The Turkish sample from Uladag Mountains (TUR_UL) locates in the morphospace close to the central Italian (ITA_ABVU) and Gargano samples. Nevertheless, it diverges from them along CA3. These molars display an anteriorly expanded area, and a prominent second lingual triangle.

\section{Molar Shape, Phylogeny and Climate}

The factors considered in the linear model included shape as a dependent dataset, and phylogeny and climate as explanatory variables.

Molar shape was described by three sets of variables: the $37 \mathrm{FCs}$, and multivariate axes summarizing more than $85 \%$ of variance (PCA: 5 axes; CVA: 10 axes).

Phylogeny was described by the first five axes of the PCOA performed on the matrix of cyt $b$ genetic distances. These axes summarized $85 \%$ of the total variance $(44.9 \%$, $22.0 \%, 11.0 \%, 6.2 \%$, and $3.7 \%$ ). Climate was estimated by the first five axes of a PCA on the climatic variables, totalling more than $95 \%$ of the climatic variance $(45.9 \%, 28.2 \%, 8.4 \%$, $10.0 \%$, and $7.2 \%$ ).
Fig. 2 Median-joining network obtained using bank voles cyt $b$ haplotypes. The size of the symbols is proportional to the number of sequences; the color indicates the lineage; dots indicate mutation steps

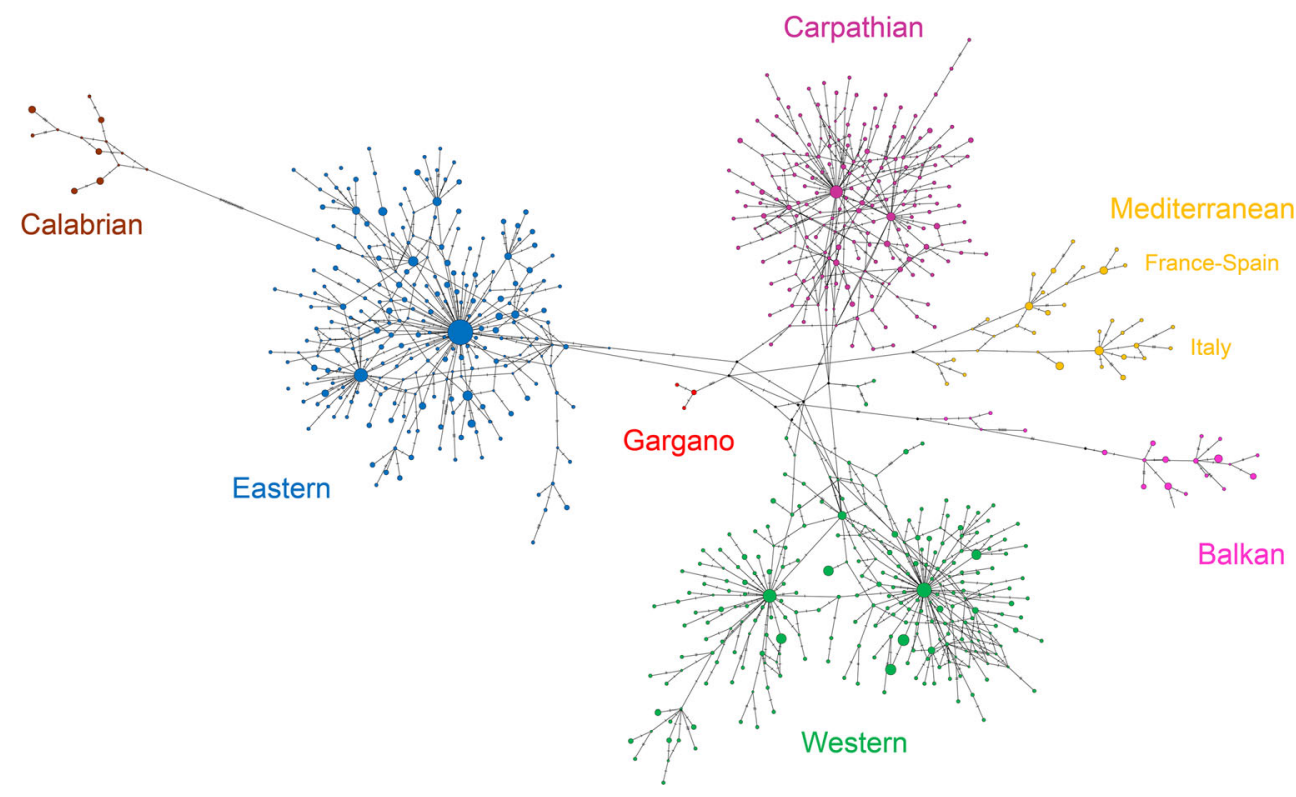


a

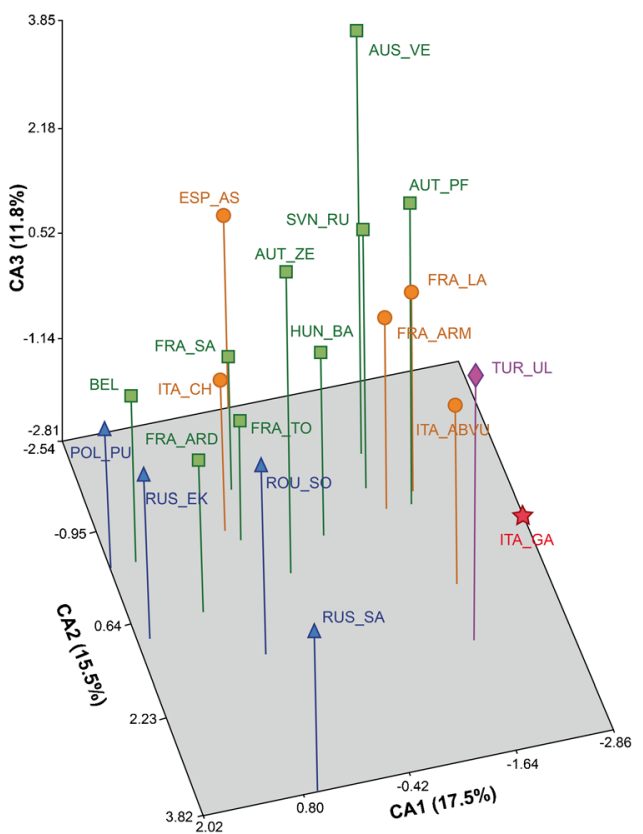

b
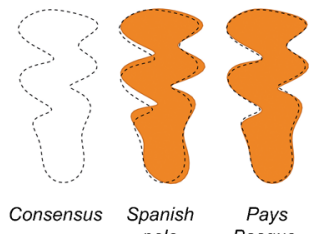
$\begin{aligned} & \begin{array}{l}\text { Spanish } \\ \text { pole }\end{array} \\ & \begin{array}{c}\text { Pays } \\ \text { Basque }\end{array}\end{aligned} \begin{gathered}\text { Italian } \\ \text { pole }\end{gathered}$
Mediterranean

Fig. 3 a Third upper molar differentiation between localities, in the morphospace based on molar outline analysis. Axes correspond to a Canonical Variate Analysis, the grouping being the localities. Colors and symbols indicate the phylogenetic lineage. b Visualization of the shape characteristic of each lineage or sub-lineage. The dotted outline correspond to the mean shape of the complete sampling (consensus), in color the mean shape of each lineage

Phylogeny and climate as well as their interaction had a significant effect in all models $(P<0.001)$ indicating an almost equal contribution of phylogeny and climate and a strong component of interaction between both factors (Table 2). The model on PCA axes explained slightly less variance than the one on all Fourier coefficients, possibly because of information lost during the drastic reduction of dimensionality. Explanatory variables

Table 2 Shape variance explained by phylogeny, climate and their interaction. Results of general linear models on three sets of shape variables: Fourier coefficients, axes of a PCA and of a CVA (axes totaling more than $85 \%$ of variance were used in the model; the corresponding number of variables is indicated). All effects were highly significant $(P<0.0001)$

\begin{tabular}{lllll}
\hline Shape descriptors & Nb Variables & Phylogeny & Climate & Interaction \\
\hline FCs & 37 & $9.2 \%$ & $6.8 \%$ & $7.9 \%$ \\
PCA & 5 & $8.5 \%$ & $6.2 \%$ & $9.4 \%$ \\
CVA & 10 & $15.1 \%$ & $14.6 \%$ & $18.7 \%$ \\
\hline
\end{tabular}

explained almost twice as much shape variance in the model on CVA axes as in the model based on PCA axes. This cannot be attributed to a lesser reduction of dimensionality because the CVA-based model also performed better as the FCs-based model. As the match between morphometrics on one side, and phylogeny and climate on the other side, was done at the scale of the locality, the explanatory variables could not explain any withingroup variation. By standardizing within-group variation, the CVA thus improved the match with the explanatory variables, here phylogeny and climate (Renaud et al. 2015a).

The variance explained by phylogeny corresponds to molar shape typical of each lineage (Fig. 3b). The variance explained by climate corresponds to a congruence between the environmental variation, displayed on the first two axes of the PCA on the bioclimatic variables (Fig. 4a, b) and the pattern of differentiation observed for molar shape. Diverging in molar shape, the Alpine localities from Austria and Slovenia are characterized by a montaneous climate. Russian localities show a continental climate. The three localities from Gargano, southern Italy, and Turkish coast of the Marmara sea share a comparable, Mediterranean climate. In contrast, the northern Italian locality (ITA_CH) shares a temperate climate with most of the Western samples. The Pays Basque displays an extreme climate with high precipitation, departing from other localities with bank voles of the Mediterranean lineage.

The effects of temperature and precipitation on tooth shape were visualized using multivariate regressions (Fig. 4c). Increasing temperature led to an expanded anterior lobe, laterally expanded second lingual and labial triangles, and a labialy expanded posterior part of the tooth. Higher precipitation led to a more strongly undulating outline.

Finally, a bgPCA was performed on the residuals of the model based on the FCs. Within-group variance explained $91.1 \%$ of the total variance, thus leaving only $8.9 \%$ of between-group variance unexplained by phylogeny, climate, and their interaction.

\section{Covariation between Morphometrics vs. Phylogeny and Climate}

Coinertia analyses provide a visual representation of how two datasets covary, for instance here phylogenetic or climatic relationships between localities on the one hand, and molar shape on the other hand. Congruence between the two datasets would correspond to short arrows. If the localities are closest according to the second dataset, arrows would converge.

Lineages are more homogeneous genetically than morphologically (Fig. 5a). Eastern and Western localities tended to display morphological convergence, except for Alpine localities (AUT_VE, AUT_PF, SVN_RU) that diverged in shape more than in mitochondrial DNA. The Mediterranean lineage appears as much more heterogeneous in shape than in phylogeny. The northern Italian ITA_CH converges towards Western 
a

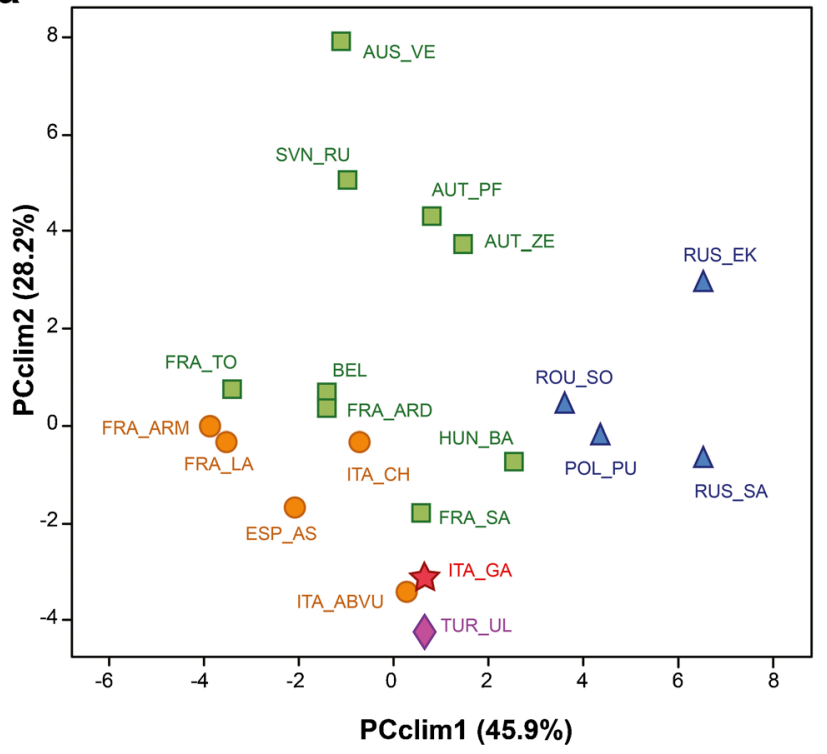

b

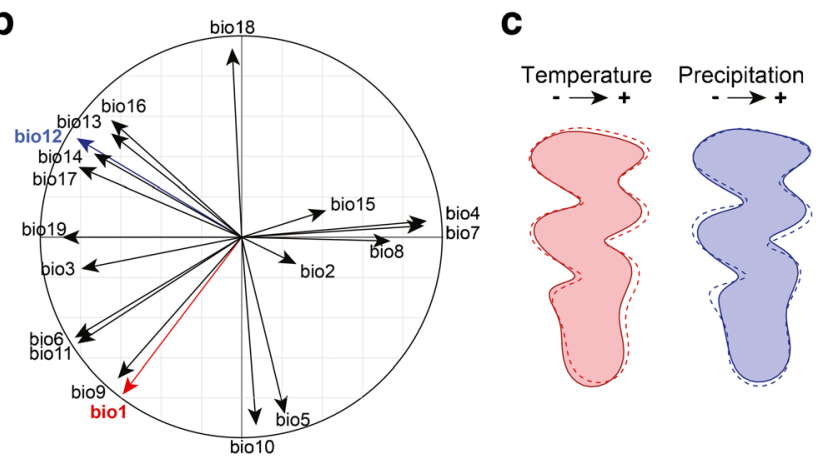

Fig. 4 Environmental variation and associated shape changes. a Variation of climatic regime across localities, shown as scores on the first two axes of a PCA on the 19 climatic variables. b Circle of correlation, showing the contribution on the PC axes of the climatic variables: $\mathrm{BIO} 1=$ Annual Mean Temperature; $\mathrm{BIO} 2=$ Mean Diurnal Range [Mean of monthly $(\max$ temp - min temp)]; BIO3 = Isothermality $(\mathrm{BIO} 2 / \mathrm{BIO} 7)(* 100)$; $\mathrm{BIO} 4=$ Temperature Seasonality $($ standard deviation $* 100) ; \mathrm{BIO} 5=$ Max Temperature of Warmest Month; BIO6 $=$ Min Temperature of Coldest Month; $\mathrm{BIO} 7=$ Temperature Annual Range $(\mathrm{BIO} 5-\mathrm{BIO} 6) ; \mathrm{BIO} 8=$ Mean Temperature of Wettest Quarter; BIO9 = Mean Temperature of Driest Quarter; BIO10 = Mean Temperature of Warmest Quarter; BIO11 = Mean Temperature of Coldest Quarter; BIO12 = Annual Precipitation; BIO13 = Precipitation of Wettest Month; BIO14 = Precipitation of Driest Month; BIO15 = Precipitation Seasonality (Coefficient of Variation); BIO16 $=$ Precipitation of Wettest Quarter; BIO17 $=$ Precipitation of Driest Quarter; BIO18 = Precipitation of Warmest Quarter; BIO19 = Precipitation of Coldest Quarter. c Variation of shape with temperature and precipitation. In red: annual mean temperature (bio1); in blue: annual precipitation (bio12). The outlines correspond to the predicted shape change with temperature and precipitation. The coloured outline corresponds to the lower range (5\% of the distribution) and the dotted outline to the upper range (95\%). This corresponds to the following values: annual mean temperature $=3.8^{\circ} / 13.4^{\circ}$; annual precipitation $=528 / 1193 \mathrm{~mm}$

localities; whereas the southern Italian ITA_ABVU diverges into another direction, converging towards the Gargano shape.
Arrows are overall shorter when considering climate vs. molar shape (Fig. 5b), showing a good match between climate and morphological differentiation. Adaptation to local conditions could be present in cases of co-differentiation of climate and morphometrics, independently of the lineage to which the bank voles belong. This is the case for three settings that strongly codifferentiate in molar shape and climate: the Alpine localities of the Western lineage (AUST_VE, AUST_PF, SVN_RU), the Russian localities (RS_SA and RS_EK), and the Gargano. The Basque Country localities (FRA_ARM, FRA_LA) also tend to co-differentiate in shape and climatic conditions from other samples; they remain close to the Asturias (ESP_AS). These three localities with an Iberian affinity are co-different in shape and climate from the Italian representatives of the Mediterranean lineage. The northern Italian ITA_CH shares a similar climatic setting and a similar molar shape with most localities documenting the Western lineage.

\section{Discussion}

\section{Vicariance and/or Adaptation: What Processes Do Shape the Bank Vole Tooth?}

Phylogeography considers vicariance as the primary source of differentiation. Divergence is assumed to accumulate in isolated populations; this process refers implicitly to neutral divergence. Evidence of selection has been looked for but remains scarce at the genetic level (Filipi et al. 2015). Adaptive genomic signature can emerge fast, however, when voles are confronted by new environments (White et al. 2013). The phenotype may be more prone to trace possible adaptive signals than mitochondrial DNA, though, because it is the target of selective pressures. Morphology, particularly of feeding structures such as teeth, are thus good candidates to look for the role of adaptation relative to neutral divergence as traced by phylogeny (Piras et al. 2009). We described a balanced role of phylogeny and environmental conditions in the divergence of tooth shape in bank voles, with some interaction between both factors. This high interaction factor may be due to congruence between the distribution of certain lineages and certain types of climate, making the effect of genetics and climate impossible to disentangle.

These results are difficult to compare with other studies, because they correspond to different teeth and shape descriptors. Cautious comparisons can still be done with other studies on rodent molars divergence based on 2D outline analysis. In house mice, molar shape differences accumulated in a short time span (thousands to hundreds years only for certain islands), with a preponderance of phylogeny followed by ecology and climate [2D outline of the first upper molar: phylogeny 7\%, ecology + climate 6\%; (Ledevin et al. 2016)]. High evolutionary rates may have been favored by the occurrence in the dataset of insular populations in very different 
a Phylogenetics $\rightarrow$ Morphometrics

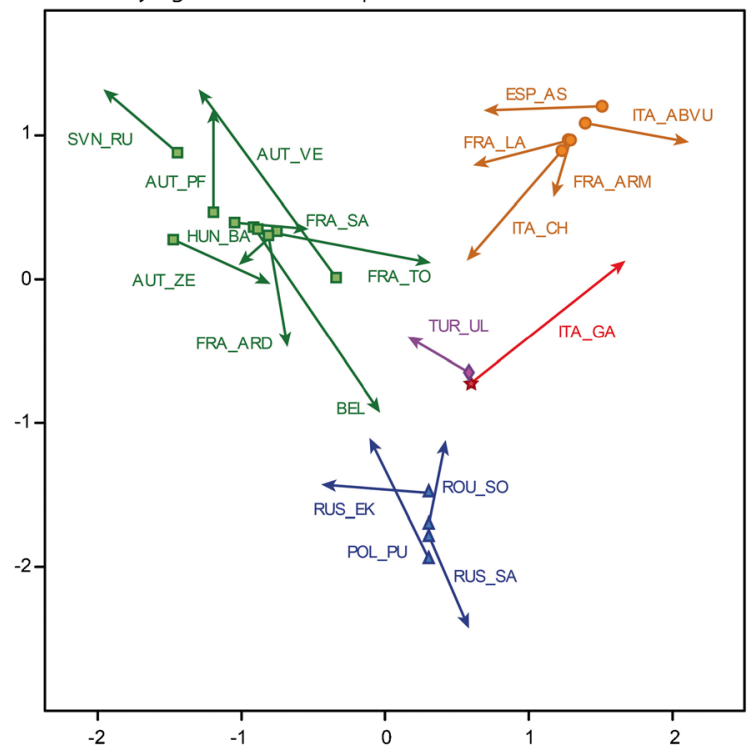

b Climate $\rightarrow$ Morphometrics

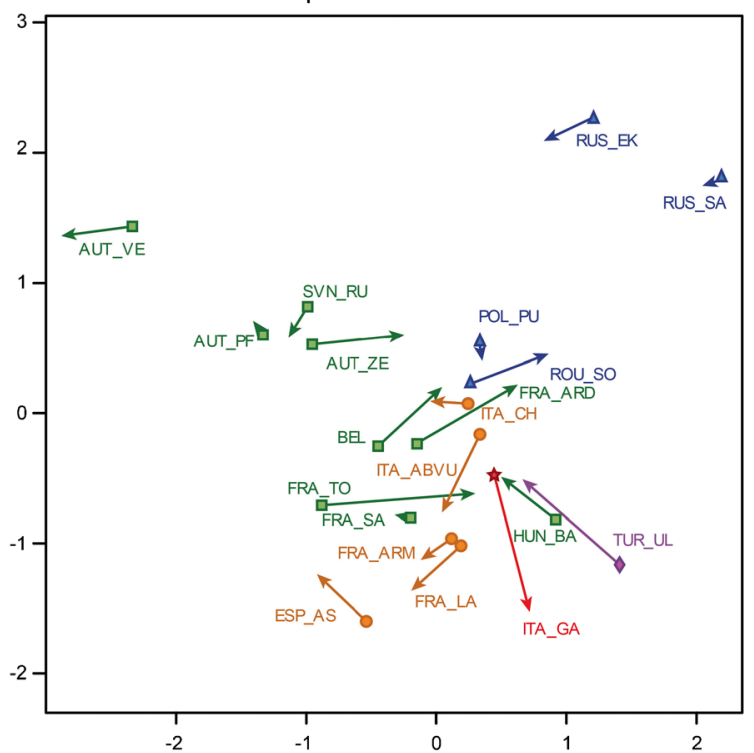

Fig. 5 Coinertia between phylogeny (a) and climate (b) vs. shape differentiation. The arrow indicates the change in topology going from the first (phylogeny or climate) to the second (shape) dataset. In color the different lineages

environmental settings. In a much longer time span $(2-5$ myrs), molar shape divergence occurred between species and sub-species of marmots (Caumul and Polly 2005) with a preponderance of diet-related factors (2D outline analysis of the third lower molar: vegetation + dietary categories: $21 \%$, phylogeny 5\%). Bank vole lineages fall between these two cases regarding timing [most lineages dating back to several 100,000 yrs (Deffontaine et al. 2005; Colangelo et al. 2012)] and the intraspecific, inter-lineage scale of divergence.

First, with increasing divergence, explanatory variables are more likely to perform better, because inter-group differences increase relative to intra-group variation. Second, the role of phylogeny seems to decrease in favor of adaptation when divergence increases. Possibly, marked ecological differences are also more likely to occur during a speciation process, triggering adaptive selection on morphological features (Renaud et al. 2007).

However, in a similar case of intraspecific, inter-lineage divergence of tooth shape in the arvicoline rodent Microtus arvalis (Renvoisé et al. 2012), tooth shape appeared under the primary control of phylogeny, climate having no traceable impact (Renvoisé et al. 2012). Possibly, the restricted geographic area considered in that study (France) limited the range of climatic conditions and thus, their possible role as selective factors promoting divergence. In contrast, by including several southern lineages of bank voles, the present study emphasized the role of adaptation and convergence in molar evolution.

\section{Morphological Convergence in Mediterranean Bank Voles}

Coinertia analyses allowed us to go a step further. Convergence in morphology (or absence of divergence) was shown between localities of the Eastern, Western, and Mediterranean lineages when sharing similar climatic conditions. Even more striking, convergent evolution was demonstrated for bank voles of warm Mediterranean areas from southern Italy, the Gargano promontory, and the Turkish side of the Marmara Sea, sharing similar morphologies despite different genetic backgrounds (Mediterranean, Gargano, and Balkan lineages, respectively).

These southern bank voles tend to share massive molars with well-developed anterior part and second triangles. A similar trend towards more robust molars was found in fossil arvicoline (Piras et al. 2009) and murine (Renaud et al. 2005) rodents during the Plio-Pleistocene. During this period, decreasing temperatures triggered an opening of the landscape, in turn favoring the consumption of harder plants. In nowadays European landscapes, harder plants may rather occur in Mediterranean areas, for instance due to adaptations to summer drought. Accordingly, broader molars have been documented in wood mice towards southern parts of Europe (Renaud and Michaux 2007; Renaud et al. 2015b). Broader molars in bank voles from warm Mediterranean areas fit this pattern, further supporting the adaptive role of this morphological signature.

In the Gargano and the Turkish populations, the evolution of this adaptive morphology occurred in the context of long-term isolation that may have favored local adaptation (Lenormand 2002). Despite belonging to the Balkan lineage, bank voles located east of the Marmara Sea seem to constitute an isolated patch, disconnected from the rest of the distribution (Fig. 1). The Gargano promontory has a long history of evolution in isolation. Being a true island during the marine transgression at the beginning of the Pliocene, 5.3 myrs ago (Freudenthal 1976), it hosted an endemic fauna typical of extreme insular 
evolution (Freudenthal 1972), including giant rodents (Parra et al. 1999). The connection of the Gargano to the Italian mainland at the early Pleistocene caused the extinction of this exceptional fauna (Masini et al. 2008). However, a certain degree of isolation may have persisted due to its peculiar geographic situation, bordered by a sedimentary basin showing sporadic occurrence of water masses during the middle and late Pleistocene (Tropeano et al. 2002 ). Isolation is probably reinforced in this area by the patchy distribution of the bank voles, at the fringe of their southern distribution (Fig. 1).

\section{Local Conditions and Geographic Barriers Favor Differentiation within Lineages}

Convergence or divergence does not only occur between lineages, but also, at a presumably shorter time scale, between populations of a same lineage. The documented cases were associated with peculiar climatic setting, suggesting the occurrence of local adaptation within lineages. The Mediterranean lineage appeared as especially exposed to contrasted climatic conditions.

The Basque Country is characterized by an oceanic climate departing from the rest of the distribution of this lineage. It is characterized by a peculiar climate/morphology association. The Basque populations were once described as a separate mitochondrial lineage (Deffontaine et al. 2009). It has been invalidated due to the occurrence of pseudogenes (Filipi et al. 2015). Nonetheless, the characteristic morphology of the Basque populations may point to local adaptation.

In contrast, central and southern Italian populations experience Mediterranean climates. This range of environmental conditions experienced within the lineage may drive the genetic differentiation found between Iberian and Italian populations. The association of French southern bank voles with the Iberian group argues for the Alps acting as barrier to gene flow (Michaux et al. 2003). The occurrence of Western haplotypes south of the Alps suggests that bank voles, contrary to wood mice (Michaux et al. 2003; Herman et al. 2016) may be able to sporadically cross this barrier, impeding the response to environmental differences.

\section{The Alps, an Ongoing Dynamics of Genetic and Morphological Diversity?}

Several Alpine localities of the Western lineage exhibited a congruent divergence in tooth shape and climatic conditions. This echoes the recent finding of a high genetic diversity and important small-scale geographic structure in Alpine bank voles (Cornetti et al. 2016). The mountainous landscape likely promotes extreme climatic differences even over a short geographic distance, and the topography may constitute barriers to gene flow. This should favor local adaptation, and the tooth shape difference documented here may trace such dynamics. Another source of diversity may be the admixture of several lineages co-occurring in the Alpine region, namely the Western, Italian, and Eastern lineages (Colangelo et al. 2012). Alpine populations may exemplify the potential for a fast, at least partly adaptive differentiation in such complex setting.

\section{Conclusions}

Mediterranean peninsulas are known as glacial refugia for many European species. Because of their complex topography, but also possibly because of climate disparity, they did not function as homogeneous units but rather as 'refugia within refugia' (Gómez and Lunt 2007; Abellán and Svenning 2014), leading to a high genetic and morphological diversity. The case of convergence documented here between Mediterranean bank voles of different lineages underlines that isolation was not the only driver of this diversity. Adaptation played a role in the long-term survival of these isolated populations, but it may have constituted a limit for these populations to recolonize more northern environments in post-glacial periods. Indeed, post-glacial recolonization of northern areas occurred from Northern refugia rather than from lineages of the Mediterranean area (Deffontaine et al. 2005; Kotlík et al. 2006).

The genetic lineages are associated to a moderate morphological differentiation, possibly because stabilizing selection in similar environments occurs in most contexts. In contrast, peculiar climatic conditions can promote adaptive differentiation between and within lineages: convergence between populations of different lineages was related to Mediterranean conditions, and morphological divergence within a mitochondrial lineage was documented in the Alpine populations.

Repeated fragmentation of the populations appeared here to promote, not reduce diversity. Exemplifying these dynamics, highly fragmented mountainous landscapes are associated with a high genetic and/or morphological diversity (Kryštufek et al. 2015; Cornetti et al. 2016). This diversity may be selected by contrasted local conditions and be favoured by isolation restricting gene-flow, altogether promoting local adaptation (Lenormand 2002). It may be further fuelled by the contact and possible admixture between lineages in the Alpine region (Tougard et al. 2008). Additional studies are required to explore this largely under-appreciated source of diversity.

Acknowledgements We thank Frank Sauvage and Jean-Pierre Quéré for having provided some of the bank voles considered in this study. The comments of Jeremy Searle and an anonymous reviewer contributed to improve this manuscript. ZH was supported by Tübitak (The Scientific and Technological Research Council of Turkey). The project EDENext supported the collection of some specimens included in this study. 


\section{References}

Abellán P, Svenning J-C (2014) Refugia within refugia - patterns in endemism and genetic divergence are linked to late Quaternary climate stability in the Iberian peninsula. Biol J Linn Soc 113:13-28

Akaike H (1973) Information theory as an extension of the maximum likelihood principle. In: Kiado A (ed) Second International Symposium on Information Theory, Budapest, pp 267-281

Amori G, Hutterer R, Kryštufek B, Yigit N, Mitsain G, Palomo LJ, Henttonen H, Vohralík V, Zagorodnyuk I, Juškaitis R, Meinig H, Bertolino S (2008) Myodes glareolus. The IUCN Red List of Threatened Species 2008: e.T4973A11104409. doi:10.2305/IUCN. UK. 2008.RLTS.T4973A11104409.en

Bonhomme V, Picq S, Gaucherel C, Claude J (2014) Momocs: outline analysis using R. J Statistical Software 56:1-24

Caumul R, Polly PD (2005) Phylogenetic and environmental components of morphological variation: skull, mandible, and molar shape in marmots (Marmota, Rodentia). Evolution 59:2460-2472

Colangelo P, Aloise G, Franchini P, Annesi F, Amori G (2012) Mitochondrial DNA reveals hidden diversity and an ancestral lineage of the bank vole in the Italian peninsula. J Zool 287:41-52

Cornetti L, Lemoine M, Hilfiker D, Morger J, Reeh K, Tschirren B (2016) Higher genetic diversity on mountain tops: the role of historical and contemporary processes in shaping genetic variation in the bank vole. Biol J Linn Soc 118:233-244

Darriba D, Taboada GL, Doallo R, Posada D (2012) jModelTest 2: more models, new heuristics and parallel computing. Nature Methods 9:772

Deffontaine V, Ledevin R, Fontaine MC, Quéré J-P, Renaud S, Libois R, Michaux JR (2009) A relict bank vole lineage highlights the biogeographic history of the Pyrenean region in Europe. Mol Ecol 18: 2489-2502

Deffontaine V, Libois R, Kotlík P, Sommer R, Nieberding C, Paradis E, Searle JB, Michaux JR (2005) Beyond the Mediterranean peninsulas: evidence of central European glacial refugia for a temperate forest mammal species, the bank vole (Clethrionomys glareolus). Mol Ecol 14:1727-1739

Dodélec S, Chessel D (1994) Co-inertia analysis: an alternative method for studying species-environment relationships. Freshwater Biol 31: 277-294

Dray S, Chessel D, Thioulouse J (2003) Co-inertia analysis and the linking of ecological data tables. Ecology 84:3078-3089

Dray S, Dufour A-B (2007) The ade 4 package: implementing the duality diagram for ecologists. J Statistical Software 22:1-20

Eronen JT, Rook L (2004) The Mio-Pliocene European primate fossil record: dynamics and habitat tracking. J Hum Evol 47:323-341

Filipi K, Marková S, Searle JB, Kotlík P (2015) Mitogenomic phylogenetics of the bank vole Clethrionomys glareolus, a model system for studying end-glacial colonization of Europe. Mol Phylogen Evol 82: 245-257

Freudenthal M (1972) Deinogalerix koenigswaldi nov. gen., nov. spec., a giant insectivore from the Neogene of Italy. Scripta Geologica 14:1-19

Freudenthal M (1976) Rodent stratigraphy of some Miocene fissure fillings in Gargano (prov. Foggia, Italy). Scripta Geologica 37:1-23

Gómez A, Lunt DH (2007) Refugia within refugia: patterns of phylogeographic concordance in the Iberian peninsula. In: Weiss S, Ferrand N (eds) Phylogeography of Southern European Refugia. Evolutionary Perspectives on the Origins and Conservation of European Biodiversity. Springer Netherlands, pp 155-188

Gouy M, Guindon S, Gascuel O, Lyon D (2010) SeaView version 4: a multiplatform graphical user interface for sequence alignment and phylogenetic tree building. Mol Biol Evol 27:221-224

Guérécheau A, Ledevin R, Henttonen H, Deffontaine V, Michaux JR, Chevret P, Renaud S (2010) Seasonal variation in molar outline of bank voles: an effect of wear? Mammal Biol 75:311-319
Guindon S, Dufayard J-F, Lefort V, Anisimova M, Hordijk W, Gascuel O (2010) New algorithms and methods to estimate maximumlikelihood phylogenies: assessing the performance of PhyML 3.0. Syst Biol 59:307-321

Herman JS, Jóhannesdóttir F, Jones EP, McDevitt AD, Michaux JR, White TA, Wójcik JM, Searle JB (2016) Post-glacial colonization of Europe by the wood mouse, Apodemus sylvaticus: evidence of a northern refugium and dispersal with humans. Biol J Linn Soc in press

Hewitt GM (1999) Post-glacial re-colonization of European biota. Biol J Linn Soc 68:87-112

Hijmans RJ, van Etten J (2014) raster: geographic data analysis and modelling. $\mathrm{R}$ package

Keller SR, Taylor DR (2008) History, chance and adaptation during biological invasion: separating stochastic phenotypic evolution from response to selection. Ecology Letters 11:852-866

Kotlík P, Deffontaine V, Mascheretti S, Zima J, Michaux JR, Searle JB (2006) A northern glacial refugium for bank voles (Clethrionomys glareolus). Proc Natl Acad Sci USA 103:14860-14864

Kryštufek B, Klenovšek T, Amori G, Janžekovič F (2015) Captured in 'continental archipelago': phylogenetic and environmental framework of cranial variation in the European snow vole. J Zool 297: 270-277

Kuhl FP, Giardina CR (1982) Elliptic Fourier features of a closed contour. Computer Graphics and Image Processing 18:259-278

Ledevin R, Chevret P, Ganem G, Britton-Davidian J, Hardouin EA, Chapuis J-L, Pisanu B, Mathias MdL, Schlager S, Auffray J-C, Renaud S (2016) Phylogeny and adaptation shape the teeth of insular mice. Proc Roy Soc Lond Biol Sc (ser B) 283:20152820

Ledevin R, Michaux JR, Deffontaine V, Henttonen H, Renaud S (2010a) Evolutionary history of the bank vole, Myodes glareolus (Rodentia : Arvicolinae): a morphometric perspective. Biol J Linn Soc 100: 691-694

Ledevin R, Quéré J-P, Renaud S (2010b) Morphometrics as an insight into processes beyond tooth shape variation in a bank vole population. PLoS One 5:e15470

Leigh JW, Bryant D (2015) POPART: full-feature software for haplotype network construction. Methods in Ecol Evol 6:1110-1116

Lenormand T (2002) Gene flow and the limits to natural selection. Trends Ecol Evol 17:183-189

Masini F, Petruso D, Bonfiglio L, Mangano G (2008) Origination and extinction patterns of mammals in three central western Mediterranean islands from the late Miocene to Quaternary. Quaternary Internatl 182:63-79

Michaux J, Chevret P, Renaud S (2007) Morphological diversity of Old World rats and mice (Rodentia, Muridae) mandible in relation with phylogeny and adaptation. J Zool Syst Evol Res 45:263-279

Michaux JR, Magnanou E, Paradis E, Nieberding C, Libois R (2003) Mitochondrial phylogeography of the woodmouse (Apodemus sylvaticus) in the western Palearctic region. Mol Ecol 12:685-697

Navarro N, Zatarain X, Montuire S (2004) Effects of morphometric descriptor change on statistical classification and morphospaces. Biol J Linn Soc 83:243-260

Paradis E, Claude J, Strimmer K (2004) APE: analyses of phylogenetics and evolution in R language. Bioinformatics 20:289-290

Parra V, Loreau M, Jaeger J-J (1999) Incisor size and community structure in rodents: two tests of the role of competition. Acta Oecol 20: 93-101

Piras P, Marcolini F, Raia P, Curcios MT, Kotsakis T (2009) Testing evolutionary stasis and trends in first lower molar shape of extinct Italian populations of Terricola savii (Arvicolidae, Rodentia) by means of geometric morphometrics. J Evol Biol 22:179-191

R core team (2015) R: A language and environment for statistical computing. R Foundation for Statistical Computing, Vienna 
Renaud S, Chevret P, Michaux J (2007) Morphological vs. molecular evolution: ecology and phylogeny both shape the mandible of rodents. Zool Scripta 36:525-535

Renaud S, Dufour A-B, Hardouin EA, Ledevin R, Auffray J-C (2015a) Once upon multivariate analyses: when they tell several stories about biological evolution. PLoS One 10:e0132801

Renaud S, Michaux JR (2007) Mandibles and molars of the wood mouse, Apodemus sylvaticus (L.): integrated latitudinal signal and mosaic insular evolution. J Biogeogr 34:339-355

Renaud S, Michaux J, Jaeger J-J, Auffray J-C (1996) Fourier analysis applied to Stephanomys (Rodentia, Muridae) molars: nonprogressive evolutionary pattern in a gradual lineage. Paleobiology 22: 255-265

Renaud S, Michaux J, Schmidt DN, Aguilar J-P, Mein P, Auffray J-C (2005) Morphological evolution, ecological diversification and climate change in rodents. Proc Roy Soc Lond, Biol Sc (ser B) 272: 609-617

Renaud S, Quéré J-P, Michaux JR (2015b) Biogeographic variations in wood mice: testing for the role of morphological variation as a line of least resistance to evolution. In: Cox PG, Hautier L (eds) Evolution of the Rodents: Advances in Phylogeny, Paleontology and Functional Morphology. Cambridge University Press, Cambridge, pp 300-322

Renvoisé E, Montuire S, Richard Y, Quéré J-P, Gerber S, Cucchi T, Chateau-Smith C, Tougard C (2012) Microevolutionary relationships between phylogeographical history, climate change and morphological variability in the common vole (Microtus arvalis) across France. J Biogeogr 39:698-712
Rohlf FJ, Archie JW (1984) A comparison of Fourier methods for the description of wing shape in mosquitoes (Diptera: Culicidae). Syst Zool 33:302-317

Schlager S (2014) Morpho: calculations and visualizations related to geometric morphometrics. R package

Taberlet P, Fumagalli L, Wust-Saucy A-G, Cosson J-F (1998) Comparative phylogeography and postglacial colonization. Mol Ecol 7:453-464

Tesakov A (1996) Evolution of bank voles (Clethrionomys, Arvicolinae) in the late Pliocene and early Pleistocene. Acta Zool Cracoviensia 39:541-547

Tougard C, Renvoisé E, Petitjean A, Quéré J-P (2008) New insight into the colonization processes of common voles: inferences from molecular and fossil evidence. PLoS One 3:1-10

Travisano M, Mongold JA, Bennet AF, Lenski RE (1995) Experimental tests of the roles of adaptation, chance, and history in evolution. Science 267:87-90

Tropeano M, Sabato L, Pieri P (2002) Filling and cannibalization of a foredeep: the Bradanic trough, southern Italy. Geol Soc Lond Spec Publ 191:55-79

White TA, Perkins SE, Heckel G, Searle JB (2013) Adaptive evolution during an ongoing range expansion: the invasive bank vole (Myodes glareolus) in Ireland. Mol Ecol 22:2971-2985

Wójcik JM, Kawałko A, Marková S, Searle JB, Kotlík P (2010) Phylogeographic signatures of northward post-glacial colonization from high-latitude refugia: a case study of bank voles using museum specimens. J Zool 281:249-262 